\title{
Pelatihan Peningkatan Mutu Produk Recycle Speaker Pada UKM Nusantara Recycle Centre
}

\author{
Recycling Speaker Quality Improvement Training At Ukm Nusantara Recycling Center
}

\author{
Sari Ayu Wulandari**1, Menik Dwi Kurniatie ${ }^{2}$, Dedi Nurcipto ${ }^{3}$ \\ ${ }_{1,2,3}$ Jurusan Teknik Biomedik, Fakultas Teknik, Udinus, Semarang

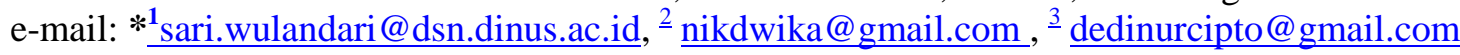

\begin{abstract}
Abstrak
Mitra kami adalah Nusantara Recycling Center (selanjutnya disingkat NRC), hingga saat ini telah mampu mendaur ulang sampah an-organik. Produk hasil dari NRC, diantaranya adalah emas, aluminium, palladium, beberapa logam lain serta sampah speaker. Pada penampungan speaker, terdapat paparan gas Freon dan gas pospor yang berbahaya bagi organ pernafasan manusia. Di satu sisi, speaker yang sudah tertampung, belum dapat dijual, karena masih belum ada yang mencari speaker bekas dalam jumlah besar. Hal ini menjadikan sebuah pemikiran, bagaimana selanjutnya pemanfaatan speaker bekas, agar lebih bernilai guna? Permasalahan dari mitra diantaranya adalah bagaimana melakukan pemanfaatan speaker bekas dilokasi mitra? Serta bagaimana meningkatkan nilai guna dari speaker bekas yang melimpah di lokasi mitra?. Solusi yang diusulkan pada pengabdian kepada masyarakat ini adalah pemanfaatan speaker bekas menjadi produk Li-Fi berteknologi tinggi. Pada kegiatan ini, dilakukan sosialisasi dan workshop pemanfaatan speaker bekas untuk Li-Fi (Light Fidelity). Urutan kegiatan dari program pengabdian ini adalah merancang workshop dan pendampingan reuse speaker, sebagai upaya transfer of knowledge dari perguruan tinggi kepada masyarakat.
\end{abstract}

Kata kunci- NRC, Li-Fi, Pengabdian Masyarakat

\begin{abstract}
Our partner is the Nusantara Recycling Center (hereinafter abbreviated as NRC), until now it has been able to recycle inorganic waste. Products from NRC include gold, aluminum, palladium, some other metals and speaker waste. At the speaker shelter, there is exposure to Freon gas and pospor gas which is harmful to the human respiratory organs. On the one hand, the speakers that have been accommodated, cannot be sold, because there is still no one looking for used speakers in large quantities. This makes a thought, how then is the use of used speakers, so that they are more valuable for use? Problems from partners include how to use used speakers at partner locations? And how to increase the use value of abundant used speakers at partner sites? The solution proposed in this community service is the use of used speakers into high-tech Li-Fi products. In this activity, a socialization and workshop on the use of used speakers for Li-Fi (Light Fidelity) was conducted. The sequence of activities from this service program is to design workshops and mentoring reuse speakers, as an effort to transfer knowledge from universities to the public.
\end{abstract}

Keywords - NRC, Li-Fi, Pengabdian Masyarakat 


\section{PENDAHULUAN}

$\mathrm{N}$ usantara Recycling Center (selanjutnya disingkat NRC), hingga saat ini telah mampu mendaur ulang sampah an-organik. Yang menarik adalah, mereka juga melakukan pengolahan sampah elektronik, walaupun masih terbilang sederhana, dengan memisahkan secara manual dan kimia.

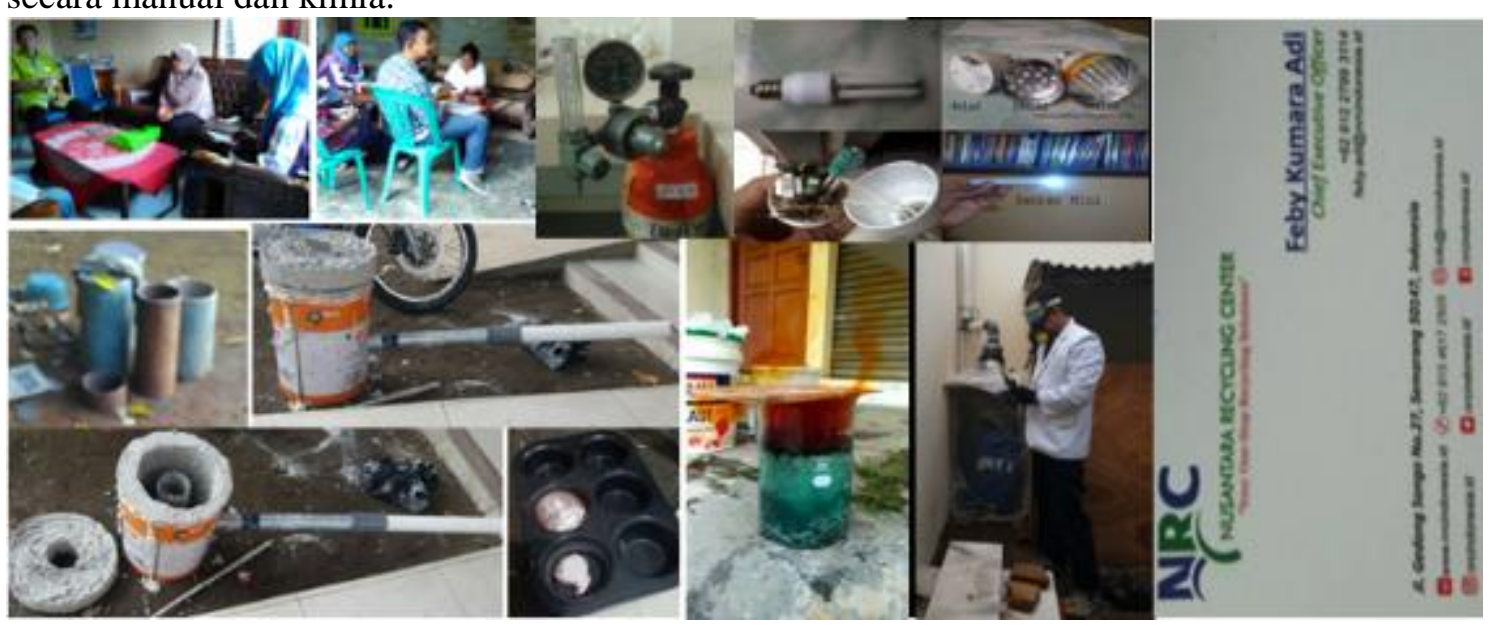

Gambar 1. Survey Lokasi Mitra NRC

Bahan kimia yang digunakan adalah $\mathrm{HNO}, \mathrm{HCl}, \mathrm{SOCl} 2$ dan beberapa zat asam pekat yang sangat berbahaya. Namun mereka tidak mengetahui, dampak dari pengolahan tersebut. Alat pengaman yang digunakan juga sangat minim. Produk hasil dari NRC, diantaranya adalah emas, aluminium, palladium, beberapa logam lain serta sampah speaker. Hasil dari pendulangan dicetak pada cetakan muffin, kemudian dijual murah. Minimnya perangkat K3 menyebabkan UMKM sering mengeluarkan biaya pengobatan Rumah Sakit, untuk kewajiban pengelolaan kesehatan bagi para karyawannya,dan tentu saja hal ini tidak murah (Gambar 1). Di satu sisi, speaker yang sudah tertampung, belum dapat dijual, karena masih belum ada yang mencari speaker bekas dalam jumlah besar. Hal ini menjadikan sebuah pemikiran, bagaimana selanjutnya pemanfaatan speaker bekas, agar lebih bernilai guna?

Dalam melakukan proses daur ulang sampah, pengelola sampah harus langsung berhubungan dengan udara yang tidak sedap. Rumah pemilik sama sama menjadi satu dengan ruang produksinya. NRC juga melakukan penimbunan sampah dengan tanpa memikirkan kadar zat metan yang dihirup oleh pekerja dan keluarganya setiap hari. Pada keehariannya, NRC melakukan sistem open dumping, yaitu mengumpulkan sampah disuatu lokasi pengolahan. Namun justru terjadi masalah baru. Gas metan yang terakumulasi pada lapisan tumpukan sampah menguap liar dan menimbulkan NRC udaranya sangat panas dan bahkan dipasang plang larangan merokok, menyalakan korek api dilokasi tersebut. Bau gas metan yang masih mengandung unsur karbondioksida, sufida dan nitrogen, menyebabkan beberapa pekerja terserang penyakit ISPA. Padahal menurut Martono, kadar metana yang diperbolehkan dalam ruangan terbatas hanya 5\% (martono, 2010). ReSpe (reuse speaker) beracun, menjadi masalah bagi para pekerja dari NRC. Karena gas beracun tidak terlihat, kadang juga tidak berbau, namun sangat menimbulkan penyakit, bahkan dalam jangka panjang bisa menyebabkan kematian. NRC sering mengeluarkan biaya pengobatan Rumah Sakit, untuk kewajiban pengelolaan kesehatan bagi para karyawannya, dan tentu saja hal ini juga tidaklah murah. Speaker bekas sangat berbahaya jika dibiarkan begitu saja tanpa ada pemanfaatan lebih. Melalui PKM ini, akan dilakukan sosialisasi dan workshop pemanfaatan speaker bekas berteknologi Li-Fi (Light Fidelity). Permasalahan mitra adalah bagaimana melakukan pemanfaatan bulb bekas dilokasi mitra dan bagaimana meningkatkan nilai guna dari bulb bekas yang melimpah di lokasi mitra? 
Komunikasi cahaya tampak (VLC) adalah istilah yang diberikan untuk sistem komunikasi nirkabel optik yang menyampaikan informasi dengan memodulasi cahaya yang terlihat oleh mata manusia. Komunikasi dilakukan dengan menggunakan lampu LED yang menyala dan mati dengan kecepatan tinggi dari apa yang terlihat oleh mata manusia. Mata bisa mendeteksi perubahan kecerahan dan kekuatan cahaya, tetapi mereka tidak dapat merasakan cahaya itu dinyalakan dan dimatikan dengan cepat. Di sisi lain, fotodioda, dapat dengan mudah mengenali modulasi on-off yang cepat. Fotodioda adalah fotodetektor yang menghasilkan arus listrik yang sebanding dengan daya optik yang terjadi di permukaan photodetektor. Prinsip sederhana ini memungkinkan komunikasi cahaya tampak teknologi yang mendukung baik pencahayaan dan komunikasi nirkabel menggunakan LED. Tidak seperti komunikasi nirkabel RF, di mana alat khusus diperlukan untuk menemukan area layanan, kehadiran area layanan VLC akan mudah terdeteksi. Spektrum yang terlihat adalah bagian dari spektrum elektromagnetik memiliki panjang gelombang dari sekitar $380 \mathrm{~nm}$ hingga $780 \mathrm{~nm}$ dan dalam hal frekuensi; ini sesuai dengan pita 385 - $789 \mathrm{THz}$ [1].

VLC telah dipahami sebagai teknik komunikasi data point-to-point pada dasarnya sebagai pengganti kabel. Standardisasi VLC ditetapkan sebagai bagian dari IEEE 802.15.7 [1]. Standar ini, saat ini sedang direvisi untuk memasukkan Li-Fi. Sebaliknya Li-Fi menggambarkan sistem jaringan nirkabel yang lengkap. Ini termasuk komunikasi multiuser dua arah, yaitu komunikasi point-to-multipoint dan komunikasi multipoint-to-point. Li-Fi juga melibatkan banyak jalur akses membentuk jaringan nirkabel optik yang sangat kecil dengan pengalihan tanpa hambatan. Ini berarti bahwa Li-Fi memungkinkan mobilitas pengguna penuh, dan oleh karena itu membentuk layer baru dalam jaringan nirkabel heterogen yang ada.

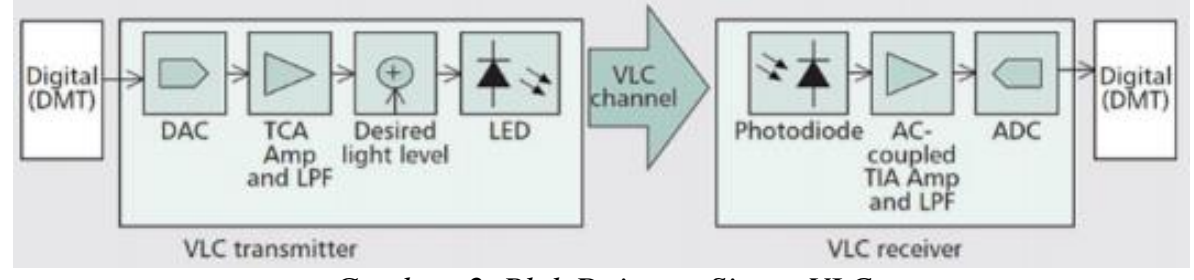

Gambar 2. Blok Daigram Sistem VLC

Li-Fi menggunakan cahaya untuk transmisi data sementara Wi-Fi menggunakan gelombang elektro-magnetik di frekuensi radio untuk transmisi data. Karena lebih sedikit gangguan yang ditimbulkan oleh cahaya dibandingkan dengan gelombang frekuensi radio, ia digunakan dalam lingkungan yang lebih padat. Pada Tabel 1 memperlihatkan tentang perbedaan mendasar antara teknologi Li-Fi dan Wi-Fi.

Tabel 1. Perbedaan Antara Li-Fi dan Wi-Fi

\begin{tabular}{|l|l|l|}
\hline \multicolumn{1}{|c|}{ Fitur } & \multicolumn{1}{c|}{ Li-Fi } & \multicolumn{1}{c|}{ Wi-Fi } \\
\hline Bentuk & Lengkap Fidelity & Wireless Fidelity \\
\hline Operasi & $\begin{array}{l}\text { Li-Fi mentransmisikan data } \\
\text { menggunakan cahaya } \\
\text { dengan bantuan lampu LED }\end{array}$ & $\begin{array}{l}\text {. Wi-Fi mentransmisikan } \\
\text { data menggunakan } \\
\text { gelombang radio dengan } \\
\text { bantuan Router Wi-Fi. }\end{array}$ \\
\hline Interferensi & $\begin{array}{l}\text { Tidak ada masalah } \\
\text { interferensi yang serupa } \\
\text { dengan frekuensi radio } \\
\text { ombak }\end{array}$ & $\begin{array}{l}\text { Akan ada masalah } \\
\text { interferensi dari akses } \\
\text { terdekat } \\
\text { poin (router) }\end{array}$ \\
\hline Teknologi & $\begin{array}{l}\text { Hadir perangkat compliant } \\
\text { IrDA }\end{array}$ & $\begin{array}{l}\text { WLAN 802.11a / b / g / } / \\
\text { ac / ad compliant standar } \\
\text { perangkat }\end{array}$ \\
\hline Aplikasi & Digunakan dalam \\
& penerbangan, eksplorasi \\
& bawah laut, teater operasi & $\begin{array}{l}\text { Digunakan untuk browsing } \\
\text { internet dengan bantuan } \\
\text { hotspot Wi-Fi }\end{array}$ \\
\hline
\end{tabular}




\begin{tabular}{|c|c|c|}
\hline & $\begin{array}{l}\text { dirumah sakit, kantor dan } \\
\text { tempat rumah untuk transfer } \\
\text { data dan menjelajah internet }\end{array}$ & \\
\hline $\begin{array}{l}\text { Manfaat } \\
\text { (keuntungan) }\end{array}$ & $\begin{array}{l}\text { Interferensi kurang, dapat } \\
\text { melewati air laut asin, } \\
\text { bekerja diwilayah padat }\end{array}$ & $\begin{array}{l}\text { Interferensi lebih banyak, } \\
\text { tidak bisa melewati air laut, } \\
\text { bekerja di daerah yang } \\
\text { kurang padat }\end{array}$ \\
\hline Privasi & $\begin{array}{l}\text { Dalam Li-Fi, cahaya } \\
\text { diblokir oleh dinding dan } \\
\text { karenanya akan } \\
\text { menyediakan transfer data } \\
\text { lebih aman }\end{array}$ & $\begin{array}{l}\text { Dalam Wi-Fi, sinyal RF } \\
\text { tidak dapat diblokir oleh } \\
\text { dinding dan maka perlu } \\
\text { menggunakan teknik untuk } \\
\text { mencapai data yang aman } \\
\text { transfer. }\end{array}$ \\
\hline Kecepatan Transfer data & $\begin{array}{l}\text { Sekitar } 1 \text { Gbps WLAN-11n } \\
\text { menawarkan } 150 \mathrm{Mbps}\end{array}$ & $\begin{array}{l}\text { Sekitar } 1 \text { - } 2 \text { Gbps dapat } \\
\text { dicapai menggunakan Wi- } \\
\text { Gig / Giga-IR }\end{array}$ \\
\hline Frekuensi & $\begin{array}{l}10 \text { ribu kali spektrum } \\
\text { frekuensi radio }\end{array}$ & $\begin{array}{l}2,4 \mathrm{GHz}, 4,9 \mathrm{GHz} \text {, dan } 5 \\
\mathrm{GHz}\end{array}$ \\
\hline Kepadatan data & $\begin{array}{l}\text { Bekerja di lingkungan padat } \\
\text { tinggi }\end{array}$ & $\begin{array}{l}\text { Bekerja di lingkungan yang } \\
\text { kurang padat karena } \\
\text { gangguan terkait }\end{array}$ \\
\hline Cakupan & Sekitar 10 meter & $\begin{array}{l}\text { Tentang } 32 \text { meter (WLAN } \\
802.11 \mathrm{~b} / 11 \mathrm{~g} \text { ), bervariasi } \\
\text { berdasarkan mengirimkan } \\
\text { daya dan jenis antena }\end{array}$ \\
\hline komponen & $\begin{array}{l}\text { Driver lampu, bohlam LED } \\
\text { (lampu) dan detektor foto } \\
\text { akan berubah sistem Li-Fi } \\
\text { lengkap }\end{array}$ & $\begin{array}{l}\text { Memerlukan router untuk } \\
\text { dipasang, perangkat } \\
\text { pelanggan (laptop, PDA, } \\
\text { desktop) disebut sebagai } \\
\text { stasiun }\end{array}$ \\
\hline
\end{tabular}

Komponen utama adalah papan Arduino Uno, LED panjang gelombang tertentu dan fotodioda. Selain komponen yang bertanggung jawab menghasilkan dan menangkap sinyal cahaya, perangkat keras tambahan diperlukan untuk menyaring dan menafsirkan sinyal-sinyal ini. Sebagai contoh, band pass filter yang cocok digunakan untuk menyaring sinyal yang masuk dengan frekuensi selain yang diinginkan; filter optik digunakan untuk menyaring cahaya dengan panjang gelombang lainnya; lensa untuk memfokuskan cahaya yang masuk, cocok jika intensitas cahayanya rendah. Dalam transmisi data digital, pengolahan sinyal digital diperlukan di kedua ujung sistem untuk memproses keluar masuknya data [2]. Tugas pemancar adalah mengubah data digital menjadi cahaya tampak. Sebuah LED merupakan komponen yang cocok karena relasinya yang relatif linear antara arus dan intensitas cahaya [3].

Penelitian tentang Lifi sudah pernah dilakukan oleh beberapa orang peneliti.diantaranya adalah index Jogi (Jogi, I, 2012) [4], T.Kuroki [5], J-Chang [6], M. Farjo [7] dan T. Vinh, dkk [8]. Chang menyatakan bahwa meningkatkan jarak celah antara elektroda pada Lifi akan meningkatkan tingkat pemindahan dari sekitar $50 \%$ sampai lebih dari $95 \%$, dengan energi masukan kumulatif sekitar 12,5 kWh / m3 (45 kJ / L). Selain itu, peningkatan jarak celah ini menghasilkan penurunan formasi produk sampingan. Efisiensi yang meningkat dengan jarak jeda yang lebih besar disebabkan oleh peningkatan ukuran yang diinduksi oleh LiFi. Diperlukan penelitian lebih lanjut untuk menguji formasi produk sampingan yang potensial [6]. Kiroki melakukan penelitian dengan menggunakan ekstrak lumut yang memiliki diameter 29, 48, 100, 202, dan $309 \mathrm{~nm}[5]$. 


\section{METODE PENELITIAN}

Adapun solusi yang ditawarkan untuk mengatasi permasalahan ini adalah dengan merancang worksop dan pendampingan reuse Lifi, sebagai upaya transfer of knowledge dari perguruan tinggi kepada masyarakat. Selain pembuatan instrument tersebut, juga diperlukan pelatihan terhadap SDM yang mengoperasikan instrumen tersebut. Urutan dari metode penerapan instrument rebu (Gambar 5). Dari rancangan akan didapatkan hasil yang maksimal melalui pengujian berikut :

1. Pengujian material bahan rancangan, sensitifitas dan lux.

2. Pengujian hasil tegangan dan arus dari lampu.

3. Bit error pada transmisi data

4. Jarak terjauh / coverage dari Li-Fi yang dirancang.

Keberlanjutan program dilakukan dengan mengadakan survey kepada mitra, dan wawancara, serta tetap melakukan komunikasi dan pendampingan setelah program PKM ini selesai dijalankan. Upaya-upaya yang dilakukan agar program ini berlanjut antara lain :

1. Memberikan pembekalan pembuatan kepada pekerja

2. Memberikan pelatihan petunjuk cara kerja dan variasi-nya.

3. Melakukan praktek langsung tat acara reparasi.

\section{HASIL DAN PEMBAHASAN}

Pembahasan terhadap hasil penelitian dan pengujian yang diperoleh disajikan dalam Pada survey awal permasalahan mitra, kami melakukan survey untuk mengetahui kebutuhan mitra. Tabel 3 memperlihatkan tentang produk yang didapat dari kegiatan mitra kami yaitu NRC. Hal ini dilakukan pada tanggal 3 Oktober 2018.

Tabel 2. Produk Hasil NRC

\begin{tabular}{|l|l|l|}
\hline \multicolumn{1}{|c|}{ Sampah } & \multicolumn{1}{c|}{ Pengolahan } & \multicolumn{1}{c|}{ Proses berikutnya } \\
\hline Organik & Kompos & Dijual ke konsumen berikutnya \\
\hline Logam & - & Dijual ke konsumen berikutnya \\
\hline Logam & Logam Olahan & Dikumpulkan \\
\hline Elektronik & Cadmium, Paladium, Emas & Dijual ke konsumen berikutnya \\
\hline Elektronik & - & Dikumpulkan \\
\hline
\end{tabular}

Pada Tabel 3 diatas, terdapat sampah yang mengumpul, namun belum dapat dijual dan belum dapat dimanfaatkan, yaitu barang elektronik, yang paling banyak adalah speaker. Ebagian elektronik dari speaker atau sering disebut dengan salon sangat minim digunakan kembali, bahkan jika diuraikan kandungannya pun hanya sedikit, lebih banyak hasil yang didapat dari penguraikan sebuah HP, sehingga tidak ada yang mencari (pembeli). Selain itu, awalnya memang sempat digunakan untuk diperbaiki dan dijual second, namun harganya masih sangat rendah. Semakin lama, speaker di mitra menumpuk dan akhirnya dibuang karena merasa barang tersebut tidak bernilai ekonomi. Hal inilah yang kemudian ditangkap oleh pelaksana pengabdian masyarakat, sebagai sebuah peluang.

Survey dilakukan pada saat pelaksanaan pengabdian masyarakat. Pada pengabdian masyarakat, terdapat 5 orang yang mengikuti kegiatan tersebut. Ke-5 orang tersebut merupakan karyawan dan owner dari NRC (Tabel 4). Tabel 4 merupakan tabel survey awal dari pengetahuan mitra. Mitra menyatakan tidak mempunyai kemampuan dasar elektronika, namun mempunyai kemampuan untuk pengetahuan tentang komponen dasar elektronika, dan bagaimana memilih komponen elektronika tersebut. Mereka sangat mengerti tentang kabeling, namun kurang bisa memilih kabel yang cocok digunakan untuk beberapa kebutuhan. Untuk masalah pengetahuan telekomunikasi, mereka kurang mengerti dan tidak mengerti banyak 
tentang cara kerja dan bagaimana komunikasi wireless itu dilakukan. Untuk pengetahuan mengenai cahaya, mereka sudah faham tentang pengetahuan dasar cahaya, diantaranya adalah bayangan dan titik focus, serta mereka juga sangat mengetahui danfaham tentang hukum pemantulan cahaya. Untuk pengetahuan tentang transfer energi, mereka tidak faham bahkan tidak mengerti bagaimana sinyal itu ditransfer, baik berupa data, suara ataupun power. Menurut survey, bahwa mereka sudah paham mengenai komponen elektronika dan bagaimana kabeling dilakukan, maka hal ini sudah cukup untuk membuat sebuah produk dengan komunikasi Lifi. Produk awal yang dikerjakan adalah Lifi Speaker. Keuntungan penggunaan lifi speaker adalah sebuah teknologi baru. Barang second, akan mempunyai kelebihan dan daya jual, jika menggunakan teknologi baru. Hal ini akan menjadi daya tarik tersendiri bagi speaker handmade buatannya. Hal inilah yang akan dilakukan dan dibuat oleh mitra, namun tentunya membutuhkan waktu untuk pengerjaan. Pada pengabdian masyarakat ini, akan dilakukan pembelajaran dan praktek langsung dengan karyawan dari Mitra Pengabdian.

Tabel 3. Survey Awal

\begin{tabular}{|c|c|c|c|c|c|c|c|c|c|}
\hline \multirow{2}{*}{ Bagian } & \multirow{2}{*}{ No } & \multirow{2}{*}{ Survey } & \multicolumn{5}{|c|}{ Responden } & \multirow{2}{*}{$\begin{array}{c}\text { Rata- } \\
\text { rata }\end{array}$} & \multirow{2}{*}{ Hasil } \\
\hline & & & $\mathbf{A}$ & $\mathbf{B}$ & $\mathbf{C}$ & $\mathbf{D}$ & $\mathbf{E}$ & & \\
\hline \multirow{5}{*}{$\begin{array}{l}\text { pengetahuan } \\
\text { Dasar } \\
\text { Elektronika }\end{array}$} & 1 & Komponen dasar elektronika & 1 & 1 & 2 & 1 & 1 & 1 & Tidak Bisa \\
\hline & 2 & Fungsi komponen elektronika & 4 & 3 & 3 & 2 & 4 & 3 & Bisa \\
\hline & 3 & Pemilihan nilai tiap komponen & 3 & 3 & 3 & 3 & 2 & 3 & Bisa \\
\hline & 4 & Kabeling & 4 & 4 & 4 & 3 & 3 & 4 & Sangat Bisa \\
\hline & 5 & Pemilihan jenis kabel & 1 & 1 & 4 & 3 & 3 & 2 & Kurang Bisa \\
\hline \multirow{2}{*}{$\begin{array}{l}\text { pengetahuan } \\
\text { dasar } \\
\text { telkom }\end{array}$} & 6 & Komunikasi wireless & 2 & 2 & 3 & 3 & 2 & 2 & Kurang Bisa \\
\hline & 7 & Komponen wireless & 1 & 1 & 2 & 1 & 1 & 1 & Tidak Bisa \\
\hline \multirow{2}{*}{$\begin{array}{l}\text { pengetahuan } \\
\text { cahaya }\end{array}$} & 8 & Titik focus dan bayangan & 3 & 3 & 4 & 4 & 4 & 4 & Sangat Bisa \\
\hline & 9 & Hukum Pemantulan cahaya & 2 & 1 & 1 & 2 & 4 & 2 & Kurang Bisa \\
\hline \multirow{3}{*}{$\begin{array}{l}\text { pengetahuan } \\
\text { transfer } \\
\text { sinyal }\end{array}$} & 10 & Transfer Data & 2 & 2 & 1 & 1 & 1 & 1 & Tidak Bisa \\
\hline & 11 & Transfer Suara & 1 & 2 & 2 & 1 & 2 & 2 & Kurang Bisa \\
\hline & 12 & Transfer Power & 1 & 2 & 1 & 1 & 1 & 1 & Tidak Bisa \\
\hline
\end{tabular}

Pelaksanaan pengabdian masyarakat dilakukan 2 tahap, yaitu pada Mitra NRC dan pada komunitas binaan Mitra NRC. Pada pelaksanaan pengabdian, team dibantu mahasiswa civitas akademika Udinus, dari program studi teknik indutri, teknik elektro dan teknik biomedis.

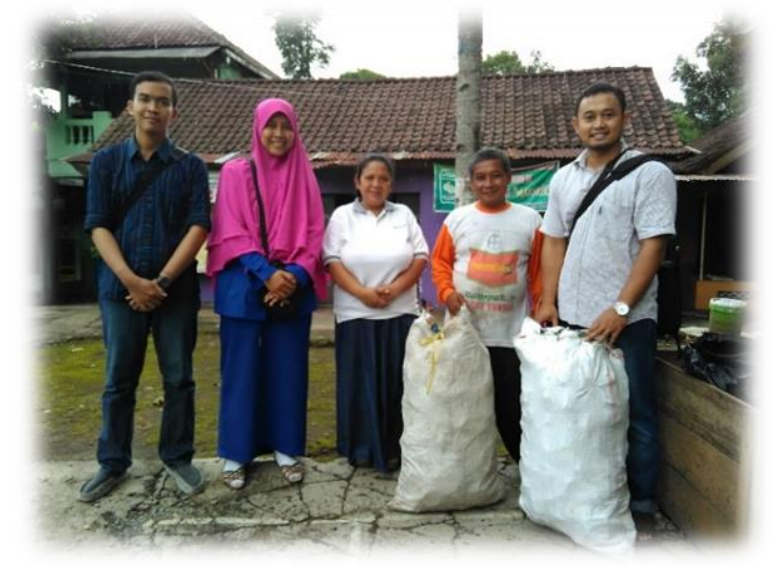

Gambar 3. Pelaksanaan Pengabdian Masyarakat

Materi yang disajikan pada pengabdian masyarakat kali ini terdiri dari 2 sesi, yaitu :

1. Pemateri dan hubungan dengan mitra Lifi ( Sari Ayu Wulandari, ST, M.Eng)

2. Reset dan penyedia peralatan serta perlengkapan pengabdian (Dedi Nurcipto, MT)

3. Pemateri dan hubungan dengan binaan mitra (Menik Dwi Kurniatie, S.Si, M.Biotech) 
Pelaksanaan pengabdian selain dilakukan dengan menggunakan slide, namun juga langsung praktek, mengingat terdapat mereka sudah mempunyai pengetahuan mengenai komponen dasar elektronika (Gambar 16). Untuk contoh alat peraga yang digunakan sebagai bahan pembelajaran dibuat di laboratorium robotika Universitas Dian Nuswantoro (Gambar 15).

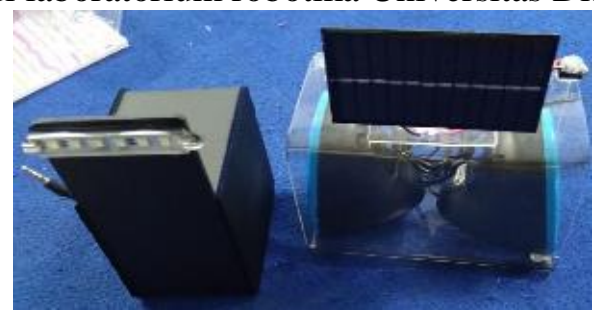

Gambar 4. Pelaksanaan Pengabdian Masyarakat

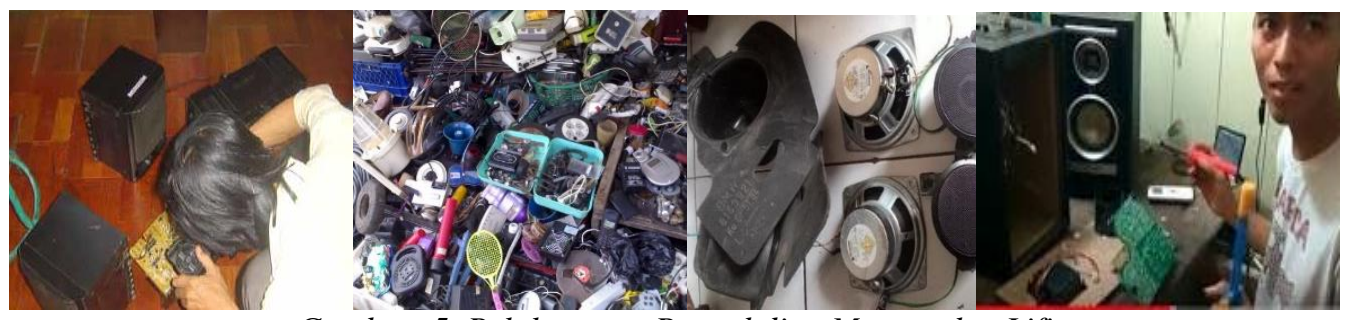

Gambar 5. Pelaksanaan Pengabdian Masyarakat Lifi

Materi pertama dilakukan pemahaman tentang efisiensi energi untuk meningkatkan pengetahuan tentang Lifi dan perbedannya dengan Wifi.



Gambar 6. Sample dari Materi Pelatihan LiFi

Setelah diberikan materi tentang pengetahuan tentang Lifi, berikutnya dilakukan pelatihan dan pendampingan, baik dari sisi produksi (inovasi) maupun dari sisi pemasaran (Bisnis model kanvas) dan pasar.

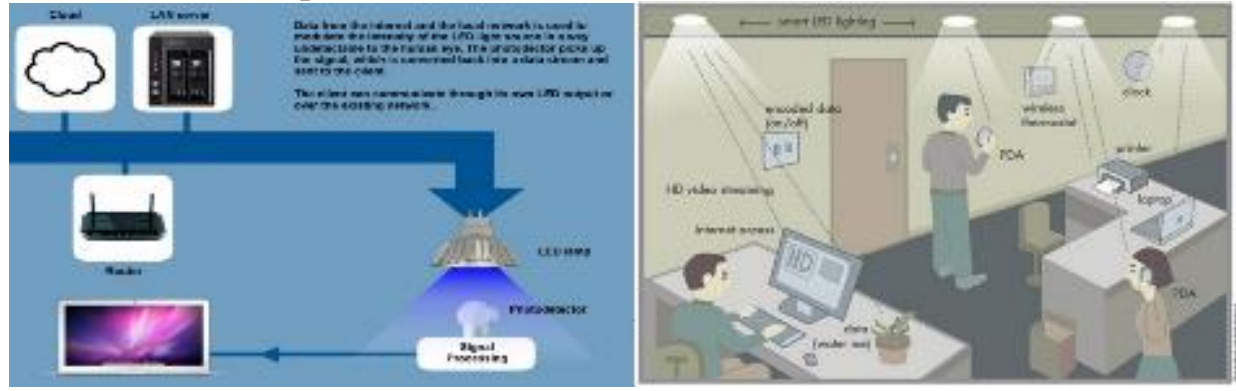

Gambar 7. Sample Pemetaan Potensi Pasar dan Perencanaan Bisnis

Pada proses berikutnya, dilakukan sosialisasi pemanfaatan sampah untuk binaan mitra yang terdiri dari 20 anak SD dan 5 orang bapak-bapak dari daerah sekitar lokasi mitra, hal ini untuk meningkatkan jumlah peserta pengabdian masyarakat. Kegiatan ini juga diprakarsai oleh mitra, dimana setiap tahun diadakan. Kegiatan yang dilakukan diantaranya adalah pemanfaatan MMT bekas untuk media tanam. 


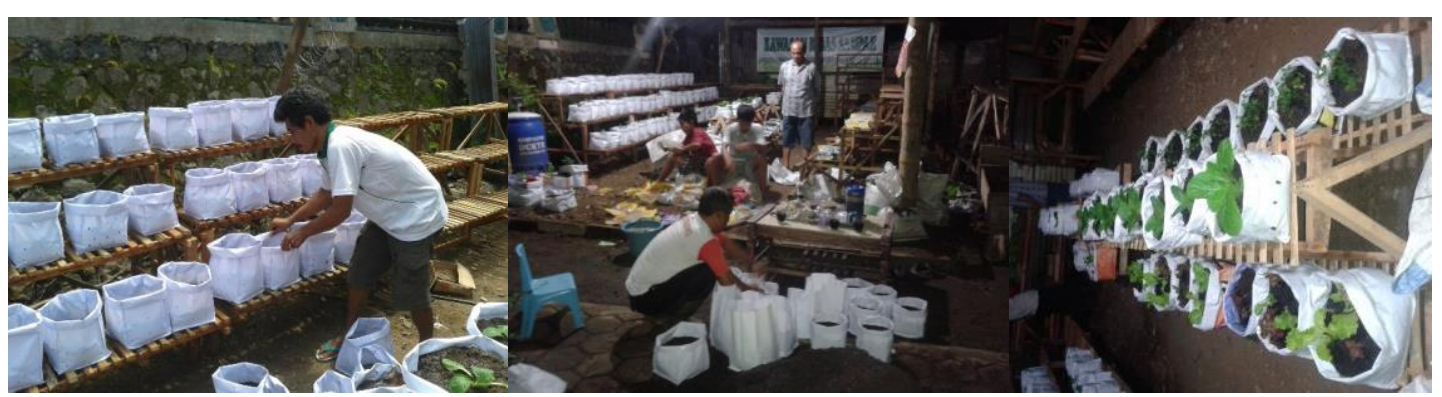

Gambar 8. Proses Pemanfaatan MMT Bekas

Pada lokasi mitra NRC, mitra binaannya juga secara aktif memasok sampah yang berupa kantong plastik, botol plastik dan sampah organik. Namun untuk selanjutnya, mitra binaan dari NRC berkomitmen untuk juga mengumpulkan elektronik untuk selanjutnya diserahkan pada NRC.

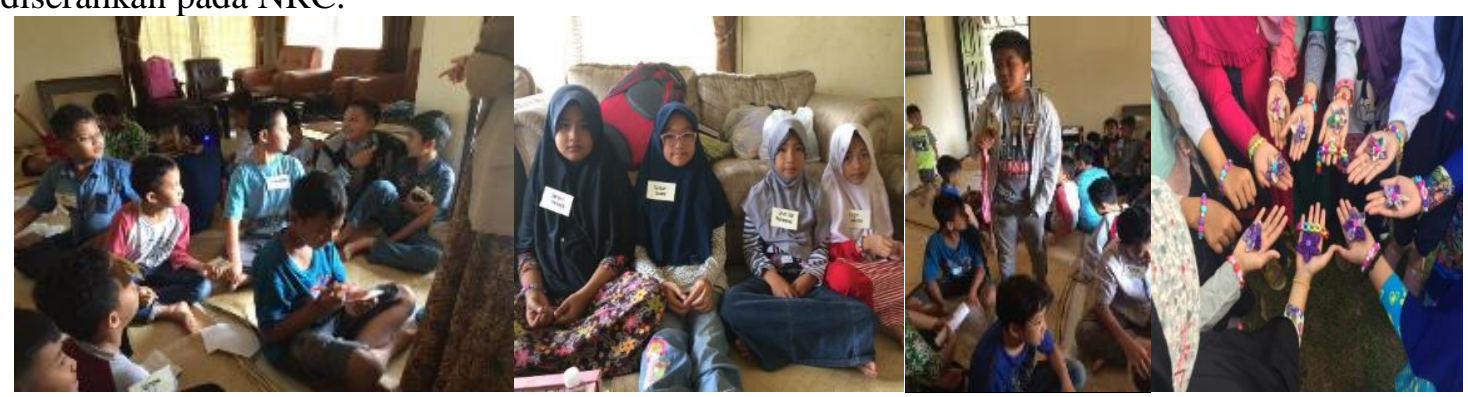

Gambar 9. Proses Pelatihan Recycle Pada Mitra Binaan

\section{KESIMPULAN}

Kesimpulan yang dapat ditarik dari pengabdian masyarakat ini adalah sebagai berikut :

1. Kegiatan yang dilakukan sudah $90 \%$. Untuk kegiatan berikutnya merupakan kegiatan penyempurnaan.

2. Untuk $10 \%$ kegiatan, dilakukan untuk penyusunan laporan akhir.

3. Pelaksanaan tatap muka kegiatan pengabdian masyarakat di NRC dilaksanakan sesuai dengan perencanaan, yaitu minimal 6 kali, dan pada pengabdian ini dilakukan selama 10 kali.

4. Adanya peningkatan daya saing masyarakat, dimana hal ini dapat diketahui dari peningkatan kualitas produk, dari speaker second yang dikumpulkan kemudian dibuang, selanjutnya menjadi speaker second yang dapat dimanfaatkan dan lebih berguna.

5. Adanya peningkatan penerapan iptek dalam proses bisnis sampah, yaitu dari proses reparasi speaker second yang dapat diterima oleh salah satu pegawai, untuk selanjutnya dapat ditularkan pada pegawai yang lain.

6. Adanya peningkatan tata nilai masyarakat, dimana masyrakat yang awalnya memandang rendah speaker second, sekarang menjadi peduli terhadap speaker, karena sudah mengetahui nilai ekonomis dari speaker second.

7. Adanya keberlangsungan dari program pengabdian kepada masyarakat di lokasi mitra.

\section{SARAN}

Saran yang dapat diberikan dari pengabdian masyarakat berikutnya adalah sebaiknya, untuk pencarian mitra dapat dilakukan dengan memahami karakteristik dari karyawan mitra, agar tidak kesulitan dalam berkomunikasi, karena biasanya, pada awal pencarian mitra, pengabdi 
masyarakat hanya berkomunikasi dengan bagian atasannya saja, padahal pelaku dari kegiatan pengabdian sebagian besar adalah karyawannya.

\section{UCAPAN TERIMA KASIH}

Penulis mengucapkan terima kasih kepada Lembaga Penelitian dan Pengabdian Kepada Masyarakat Universitas Dian Nuswantoro yang telah memberi dukungan financial terhadap pengabdian masyarakat ini.

\section{DAFTAR PUSTAKA}

Chang, J. (n.d.). Thermal Bulb Solid Waste and Water Treatments : A Critical Review What Is Bulbs Solid Liquid Gas, 67-84.

Correale, \& Raffaele. (2011). (2) Patent Application Publication (10) Pub. No.: US 2011/0006202 A1, 1(19).

Farjo, M. (n.d.). A Novel NOx and Particulate Matter Filter Using Non-Thermal Bulb ( NTP ), 15.

Indrek Jõgi, Brandenburg, R., Schwock, Alexander, Cameron, D., \& Ulrich.., J. J. and K. (n.d.). Bulb Treatment for Environment Protection, 1-106.

Jolla, L., \& Diego, S. (2001). ( 12 ) United States Patent, 29(5).

Jolla, L., Diego, S., Bosco, D., \& Bosco, D. (2000). United States Patent [ 19 ].

Kuroki, T., Nishii, S., Kuwahara, T., \& Okubo, M. (2016). particle removal and exhaust gas cleaning using a gas-liquid interfacial nonthermal bulb, (2), 1-13.

Kurup, P. U., \& Nashua. (2006). (2) Patent Application Publication (10) Pub. No.: US 2006/0191319 A1, l(19).

Leal-quir, E. (2017). Bulb Processing of Municipal Solid Waste, 34(4), 1587-1593.

Muresan. (2013). ( 2 ) Patent Application Publication ( 10 ) Pub . No .: US 2013 / 0061692 A1, $1(19)$.

Rani, D. A., Gomez, E., Boccaccini, A. R., Hao, L., Deegan, D., \& Cheeseman, C. R. (n.d.). Bulb treatment of air pollution control residues.

Vinh, T. Q., Watanabe, S., Furuhata, T., \& Arai, M. (2012). Fundamental study of NO x removal from diesel exhaust gas by dielectric barrier discharge reactor $\uparrow, 26(\mathrm{x}), 1921-$ 1928. https://doi.org/10.1007/s12206-012-0402-y 